\title{
Global Response for Capacity Building of Disaster Preparedness: A TIEMS Initiative
}

\author{
K. Harald Drager \\ The International Emergency Management Society (TIEMS) \\ Thomas V. Robertson \\ Thinking Teams
}

\begin{abstract}
At the end of 2013, the devastating consequences of the Typhoon Haiyan that struck the Philippines on November 8, 2013, were exposed worldwide through intensive media coverage. The death toll reached more than 6,000 people, and around one million people were displaced and in desperate need of help and support. The international community queued up to offer support and help and showed that worldwide solidarity works when we know our "brothers and sisters" are in desperate need of help. But how can this international community, eager to respond when disaster strikes, better help before disasters strike? Vulnerable areas in the world where people are unprepared are mostly known; educational material, early warning systems, shelters, and other means of preparedness are available; it is estimated that $\$ 1$ spent on preventative measures saves up to $\$ 7$ in emergency response and rehabilitation. It is our conviction that global preparedness can be improved by creating an international base of shared knowledge and expertise in emergency management and by engaging the international aid community to help build disaster resilience in the places where it is needed most. The International Emergency Management Society (TIEMS) invites participation in an international initiative, Disaster Resilience Establishment in Vulnerable Societies (DREVS), to work toward these goals, making risk management and disaster preparedness a part of cultures throughout the world.
\end{abstract}

\section{INTRODUCTION}

The fact that the population of the globe is rapidly growing concomitantly with the ever-increasing impact of natural and man-made disasters is not coincidental. Civil strife, stress on the environment, immense demand for energy, and rapid rise of economies in developing countries are the result of this convergence. It is not surprising, then, that the loss of life and damage to physical property has increased so significantly in developing countries (Scholtens, 2008; Bandyk, 2010). Although a disaster may cause physical effects in a single nation, it produces ripples that are felt in neighboring nations and can cause long-term impacts on productivity, growth, and the economies throughout the world.

Effective, efficient response and rehabilitation capabilities/mechanisms are equally important to minimize and redress disaster losses and damages. It is estimated that in 2013, over $\$ 69$ billion was spent worldwide on emergency and incident management (Research and Markets, 2014). Despite the need, or perhaps because of it, there is great variability concerning the level of cooperation and coordination that exists at all levels. Cooperation and coordination varies from community level to local, village, municipality, district/province, and region. At the international level (Kahn, 2005) it also varies from regional to global. Just as the number and severity of disasters are increasing across the globe, so are social and economic costs of disasters and global humanitarian challenges increasing in scope and complexity. The need and importance of cooperation and coordination among the national/international organizations and countries is pertinent, particularly in the development of humanitarian assistance.

This situation calls for attention to the need for solid cooperation and coordination among government authorities, international organizations, and NGOs for effective disaster management (Hagen, 2012). Cooperation is considered by many as the best way to marshal the diverse players in pursuit of their common humanitarian goals. In addition, since the impact of a disaster in a particular country or region can have a multitude of effects in other countries or regions, cooperation and coordination are needed to effectively accommodate the interests of diverse stakeholders.

Recognizing importance and scope of emergency management, the international community has developed a variety of organizations and coordination mechanisms, for example, the United Nations Office for the Coordination of Humanitarian 
Affairs (OCHA). However, coordinating emergency response is inherently difficult. Two particular barriers to effective response have been identified (Jaurequi, Sholk, Radday, \& Stanzler, 2011):

1. Insufficient coordination among actors due to divergent priorities and values, limitations to mandates, unaligned information collection and sharing, and inexperienced staff and organizations

2. Limited involvement of affected populations and governments in response.

While coordinating international emergency response will always be a complex organizational and political endeavor, an International Emergency Management Society (TIEMS) initiative, Disaster Resilience Establishment in Vulnerable Societies (DREVS), is working to strike at the core of this challenge, by:

1. Establishing a better basis for international coordination through a standardized base of emergency management knowledge, inclusive of and adaptable to local knowledge and conditions

2. Working to help the international aid community place a greater emphasis on preparedness.

It is vital that those in charge of complex and multisectoral/multinational emergency operations be trained and educated in the basic competencies of emergency management. It is clear that as the largest countries struggle with the pressing need for disaster management, there has been an increasing interest in structured and consistent disaster management education of first responders and emergency managers. Developing nations have a critical need for structured learning programs. In the United States, although there has been great activity in creating academic programs at all levels, there is much work on standardization yet to be done. An international perspective must be taken on what the most important knowledge and skills would be for basic training in emergency management. Emergency managers must be educated and trained in the management skills of leadership, teams and team building, and conflict resolution. They must also have great respect for the experiential knowledge possessed by all nations as well as by the indigenous peoples of the world.

In addition to developing expertise and shared knowledge in emergency management, the international community can benefit from an approach to preparedness that is informed by global experience and priorities. In this paper, we suggest elements of such an approach, based on the TIEMS international perspective.

\section{WORLD DISASTER PICTURE, 2003-2012}

From World Disasters Report 2013 (International Federation of Red Cross and Red Crescent Societies [IFRC], 2013), an overview of disasters in 2012 is shown in Figures 1 and 2.

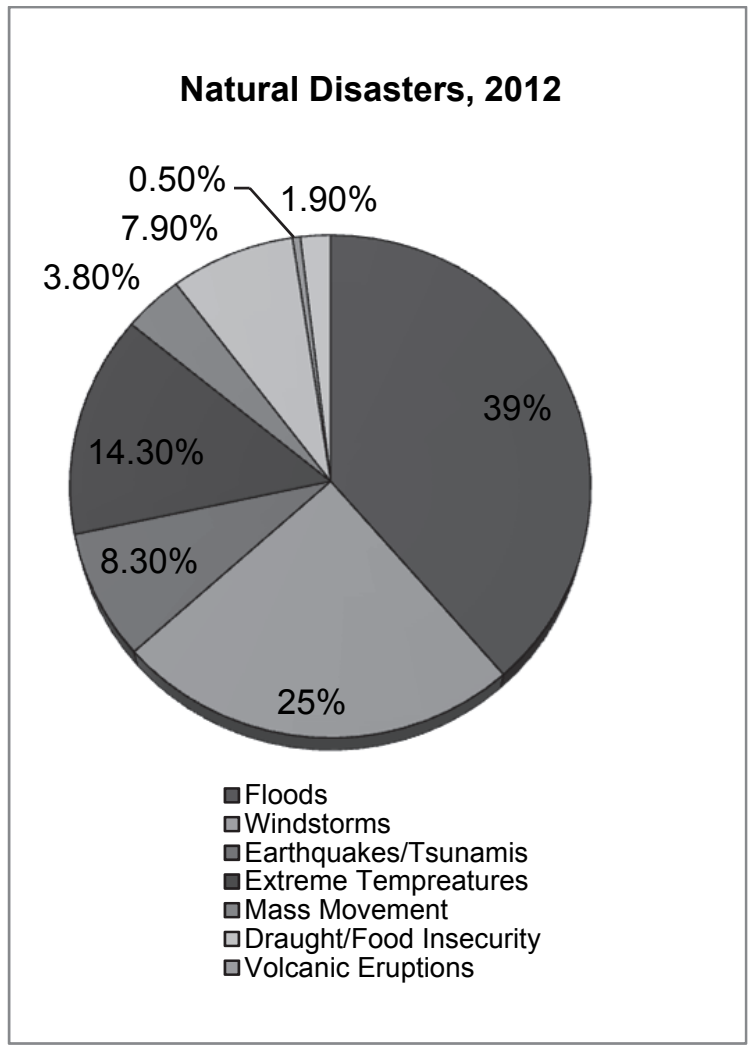

Figure 1. Natural disasters, 2012

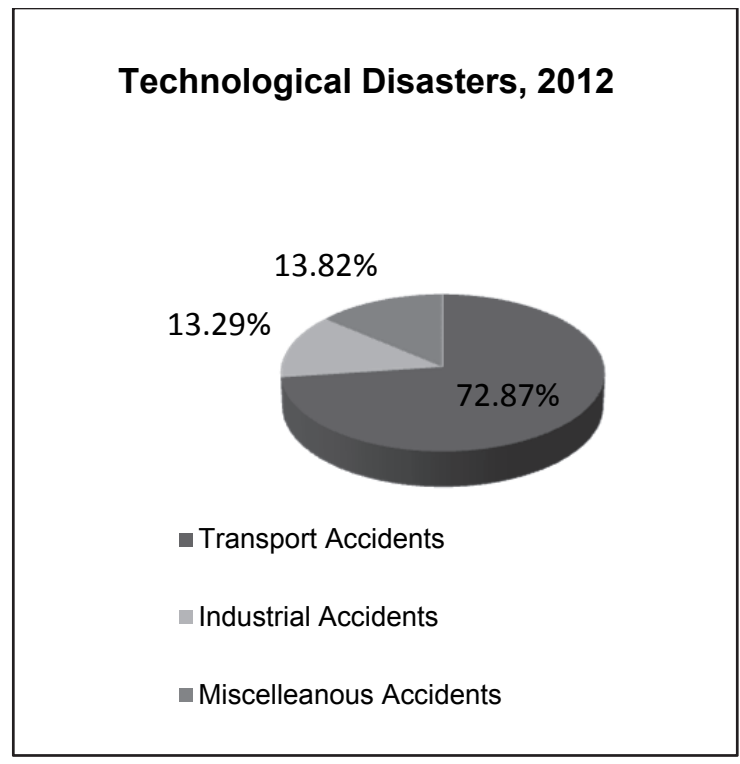

Figure 2. Technological disasters, 2012 
Table 1. Disaster characteristics for the period 2003-2012

\begin{tabular}{|c|c|c|}
\hline $\begin{array}{l}\text { DISASTER } \\
\text { CHARAC- } \\
\text { TERISTICS }\end{array}$ & MOST SEVERE & SECOND WORST \\
\hline $\begin{array}{c}\text { NATURAL } \\
\text { DISASTER } \\
\text { TYPE }\end{array}$ & $\begin{array}{c}\text { FLOODS, } 39 * \%(2012) \\
\text { STEADY/ } \\
\text { FLUCTUATING } \\
2003-2012\end{array}$ & $\begin{array}{c}\text { WIND STORMS, } 25^{*} \% \text {; } \\
\text { STEADYI } \\
\text { FLUCTUATING } \\
2003-2012\end{array}$ \\
\hline $\begin{array}{l}\text { TECHNICAL } \\
\text { DISASTER } \\
\text { TYPE }\end{array}$ & $\begin{array}{c}\text { TRANSPORT ACCIDENTS, } \\
72^{*} \% ; \\
\text { DECREASING } \\
2003-2012\end{array}$ & $\begin{array}{l}\text { INDUSTRIAL } \\
\text { ACCIDENTS, 13*\%; } \\
\text { DECREASING } \\
2003-2012\end{array}$ \\
\hline $\begin{array}{l}\text { DISASTER } \\
\text { LOCATION }\end{array}$ & $\begin{array}{c}\text { ASIA, 38*\% } \\
(\mathbf{2 0 1 2 )} \\
\text { SLOWLY DECREASING } \\
2003-2012\end{array}$ & $\begin{array}{l}\text { AFRICA, } 22 * \%(2012) \\
\text { SLOWLY } \\
\text { DECREASING 2003- } \\
2012\end{array}$ \\
\hline $\begin{array}{l}\text { DISASTER } \\
\text { DEATHS }\end{array}$ & $\begin{array}{c}\text { ASIA, 54*\% } \\
\text { (2012 DOWN) } \\
\text { FLUCTUATING } \\
\text { 2003-2012 }\end{array}$ & $\begin{array}{c}\text { AFRICA, } 19 * \%(2012) \\
\text { STEADY } \\
2003-2012\end{array}$ \\
\hline $\begin{array}{l}\text { AFFECTED } \\
\text { POPULATION }\end{array}$ & $\begin{array}{c}\text { ASIA, 65*\% } \\
\text { (2012 DOWN) } \\
\text { STEADY } \\
2003-2012 \\
\end{array}$ & $\begin{array}{c}\text { AFRICA, } 31^{* * \%} \% \\
\text { (2012 UP) } \\
\text { STEADY } \\
2003-2012 \\
\end{array}$ \\
\hline $\begin{array}{l}\text { COST OF } \\
\text { DAMAGE }\end{array}$ & $\begin{array}{l}\text { AMERICAS, 66\%* } \\
\text { (2012 UP) } \\
\text { FLUCTUATING } \\
2003-2012\end{array}$ & $\begin{array}{l}\text { ASIA, 18\%* } \\
\text { (2012 DOWN) } \\
\text { FLUCTUATING } \\
2003-2012\end{array}$ \\
\hline
\end{tabular}

Table 1 summarizes the disaster picture and consequences for the period of 2003-2012:

Floods and transports are the most severe natural and technological disasters, respectively, in the period of 2003-2012. While a positive downward trend is seen for transport accidents in this period, the flood disasters seem to be steady but fluctuating over the period. Most disasters happened in Asia during the period, with a slowly decreasing trend in Asia and Africa. Asia also had the most deaths after disasters, $54 \%$ of the world total in 2012, while Africa had $22 \%$ in 2012. Deaths in Asia have been fluctuating over the period of 2003-2012, while it has been quite steady in Africa.

The population in Asia has been most affected, with $65 \%$ of the area's population impacted by disasters in 2012, with a steady trend in the period of 20032012. Thirty-one percent of Africa's population was affected in 2012, which also was a steady trend in the period of 2003-2012.

The cost of damage was highest in the Americas with $66 \%$ of the world total in 2012 and $18 \%$ in Asia. The high total in the Americas is mostly due the heavy costs after Hurricane Sandy.

The overall picture is that floods are the number one disaster, and Asia is the continent most affected by disasters. These figures and conclusions should be very clear indicators of how and where to prioritize activities for Disaster Risk Reduction.

\section{OBSERVATIONS FROM A RECENT DISASTER}

At the end of 2013, we were shocked by the devastating consequences of Typhoon Haiyan that struck the Philippines on November 8, 2013. The terrible death toll increased each day and reached more than 6,000 , and more than one million people were displaced and in desperate need of help and support. The media channels brought us shocking pictures every day, so the tragedy was exposed in all its cruelty in our homes.

The international community was ready to help and support the victims of the catastrophe. Many of us living in peaceful environments far away from the tragedy in the Philippines queued up to offer support. This is good, and it shows that we react and help when our "brothers and sisters" in this world are in desperate need.

But what about helping the Philippines to improve their resilience through preparedness programs before the disasters strike?

Typhoons come every year, maybe not as powerful as Haiyan, but the need for shelters and early warning must have been evident to all for a long time before the recent tragedy. If we also add earthquakes, landslides, and other disasters hitting the Philippines from time to time, the question is, could international aid to improve early warning and preparedness do a better job of saving lives and property than aid provided only after disasters, such as Haiyan, strike? Perhaps our global community can learn from this recent tragedy, to invest more help and assistance in those areas we know will be hit, before disasters strike.

A glimpse into the vulnerability of the Philippines and its openness to help is provided in recent personal correspondence from Ricardo Q. Cabugao, Jr., Chairperson of the Information Technology Education Department of Batanes State College, Basco, Philippines. Mr. Cabugao, who is also a part of the School of Disaster Risk Reduction and Management Council, writes that Batanes State College, located on a small island in the northernmost tip of the Philippines, is prone to natural disasters including earthquakes, typhoons, landslides, tsunamis, and tidal waves. For example, on September 21, 2013, the island was struck by Super Typhoon Odette (Usagi), leaving damaged roads, bridges, and lines of communication. Natural disasters have displaced the Ivatan indigenous people on the island, who have had to relocate to Mindanao and Visaya. Concerning the TIEMS DREVS initiative, Mr. Cabugua states he is more than willing to "...undergo trainings...to equip 
[himself] with the knowledge, skills, and attitudes needed in times of calamities..." in support of "...disaster-resilient and safer communities on our country, as well as in the international arena when the need arises." $\mathrm{He}$ is also eager to "...submit research proposals to be funded related to disaster risk reduction and management."

Disasters, such as those experienced in the Philippines, lead to the following conclusions:

1. Building disaster preparedness will reduce the devastating consequences of natural disasters in vulnerable countries

2. Vulnerable countries with limited resources need to get professional help with their disaster preparedness

3. Disaster preparedness should be based on risk assessments identifying potential threats and means to deal with these threats

4. The goal must be to provide help building up local expertise to "help the country to help themselves in a critical situation"

5. Education and training of locals, offering courses on all levels from universities to primary schools, are the key to create a risk management culture in the vulnerable countries

6. Media could play a role putting a focus on the preparedness challenges in vulnerable countries and stimulating the willingness of the international community to donate financially to build up preparedness and create resilient societies

7. An international organization is needed to be the central coordinating organization of this effort. Today, the United Nations is probably the best international organization to take on this task, but other international organizations should also be considered

8. A cooperation model needs to be established to allow all qualified stakeholders in the global emergency management sector to participate and contribute to building resilient societies

9. The receiving countries must likewise be helped to build local expertise able to manage the local situation and manage the preparedness projects

10. There must be a focus on reducing aid administrative costs so most of the means collected goes to the activity planned

11. Control mechanisms for disaster preparedness projects should be established that measures effectiveness and economics, and insures projects are managed according to schedule and budget

In the following sections, we review more general observations and lessons learned from the international community concerning the challenges of disaster preparedness. We first address the foundation of global resilience-local, country preparedness. Next, we address needs, opportunities, and responsibilities associated with international cooperation to develop global disaster preparedness.

\section{LOCAL PREPAREDNESS}

Disaster prevention and preparedness require a wide range of measures, both long and short term, aimed at saving lives and limiting the amount of damage caused. Particularly, confronting recurrent calamities is a stupendous task, with attendant regulatory, institutional, resource, and technological and managerial prerequisites (Chhetri, 2001). Some of the more pertinent challenges that need to be addressed are highlighted below:

- It is imperative that each country take into account the unprecedented local impacts of global warming, green house effects, and climate change when planning a multihazard early warning system or network, and in formulating and implementing disaster management policies.

- Emergency managers must be educated and trained in core competencies related to coordinating response to large, complex disasters. There must be a focus on mentoring leadership and working with teams on an intersectoral, interdisciplinary, and international basis.

- There needs to be a comprehensive and unified disaster management policy to reduce the social and economic costs to the community caused by disasters. The policy should properly address problems in urban, suburban, and rural areas.

- The link between environment and infrastructure in the region needs to be understood and accounted for in disaster planning

- Experiences, ideas, and strategies should be shared with all stakeholders as part of an inclusive planning and execution process.

Local preparedness enables and is enhanced by international cooperation. We address some of the associated challenges and opportunities in the next section. 


\section{INTERNATIONAL COOPERATION}

In addition to the intercountry cooperation and coordination among disaster management stakeholders, there is a growing need for regional, international, and global cooperation and coordination among the countries that have common problems, as a country's disaster situation may affect many other nations. For example, an earthquake disaster can have wide geographical coverage. Where much of the region's transport and communications infrastructure crosses several borders, the need for regional-level services is obvious. Similarly, failure to apply disaster risk management in any one country can affect such infrastructure and, thus, the region as a whole.

The Gisjlegen disaster in Belgium is an example of international cooperation and optimized coordination in the area near the border of Belgium and France (Steiner, personal communication, 2013). An accident at a pumping station in Belgium, very near the French border, resulted in many burn casualties, exceeding the capacity of local hospitals. Through effective international cooperation, special burn hospitals in the north of France were used to treat victims. A potentially complex international operation hindered by geographic boundaries, sectors, and jurisdictions was carried out successfully.

Regional and international cooperation is essential not only to cope with the impacts of disaster but also to help ensure that the region sustains economic growth. Moreover, enhanced regional and international cooperation and coordination in disaster risk management offers attractive opportunities to provide resources. Disaster preparedness has remained inadequate in many countries where lack of national-level updated disaster legislation hinders national focal agencies in interinstitutional and intergovernmental coordination.

Many aspects of disaster management are transborder. As a result, those countries could be economically and socially affected due to the serious natural disasters in a neighboring country. A neighbor may be able to provide valuable help in evaluating risk; mitigating, forecasting, developing, and communicating early warnings; and responding to disasters. There is incredible value in utilizing international and indigenous knowledge systems when facing the challenges of reconstruction following disaster (Hagen, 2010; Hagen \& Hagen, 2013). Regional planning and joint efforts are needed to solve disaster problems because disasters involve uncertainty and they are major concerns for all countries.

Countries that have common goals and interests should share disaster data and information so as to reduce the impact of potential disasters. International cooperation is critical to find more effective ways to forecast risk, to better manage the response, and to develop organizational resilience to interruption and different types of crisis and disasters (Chhetri, 1999).

In addition to the importance of national-, regional-, and international-level cooperation and coordination, there is also the need for enhanced cooperation and coordination at the United Nations. In particular, there needs to be improved coordination between the:

- United Nations Office for the Coordination of Humanitarian Affairs (UN-OCHA),

- United Nations Human Settlements Program (UN-HABITAT),

- United Nations Disaster Relief Organization (UNDRO) and United Nations International Strategy for Disaster Reduction (UNISDR),

- World Meteorological Organization (WMO), and

- United Nations Environmental Program (UNEP).

NATO and the EU also play an important role in this area. Cooperation also needs to include the EuroAtlantic Disaster Response Coordination Centre (NATO-EADRCC) and the Emergency Response Coordination Centre (EU-ERCC [Ministry of Home Affairs, 1998]). EADRCC is a $24 / 7$ focal point for coordinating disaster relief efforts among NATO members and partner countries. ERCC (formerly $\mathrm{MIC}$ ), based at the European Commission in Brussels, is accessible 24/7 and can spring into action immediately when it receives a call for assistance. The ERCC works in close cooperation with national crisis centers throughout the 32 countries participating in the Community Mechanism for Civil Protection (which includes the EU 28, the former Yugoslav Republic of Macedonia, Iceland, Liechtenstein, and Norway).

The World Bank, in association with the Global Facility for Disaster Reduction and Recovery, has provided technical and financial support to over 20 countries seeking to improve disaster risk management. For example, their Mozambique Water Resources Development Project is a 6-year project that includes goals for improved flood management and mitigation.

Moreover, there are a number of international NGO's and other international organizations which can offer valuable help and expertise supporting international collaboration. TIEMS, described in the following section, is an example of an NGO working as part of the international community to achieve better global disaster preparedness. 


\section{THE INTERNATIONAL EMERGENCY MANAGEMENT SOCIETY (TIEMS)}

TIEMS was founded in 1993 in Washington, D.C., and is today registered as an international, independent, nonprofit NGO in Belgium. TIEMS is an international network of users, planners, researchers, industry, managers, response personnel, practitioners, social scientists, and other interested parties and individuals concerned with emergency and disaster management.

TIEMS provides a platform for all stakeholders within the global emergency and disaster management community to meet, network, and learn about new technical and operational methodologies. It also aims to exchange experiences with good industry practices including the best from different risk cultures. The belief is that this will influence policy makers worldwide to improve global cooperation and to establish global standards within emergency and disaster management.

TIEMS stimulates the exchange of information regarding the use of innovative methods and technologies within emergency and disaster management. In this way, it will improve society's ability to avoid, mitigate, respond to, and speedily recover from natural and technological disasters. TIEMS is building a network of experts through local TIEMS chapters all over the world, with the aim to "think globally and act locally." TIEMS chapters are self-governed entities within the TIEMS framework. Today, chapters are established in Italy, Iraq, Romania, Be/Ne/Lux, India, Finland, the Middle East and North Africa (MENA), Japan, Korea, and China.

Dialogue is also opened with experts in more countries, which see the benefits of TIEMS's international expert network where partnership, education, and research in disaster resilience is the focus in local activity, and where culture differences are put on the education and research agenda.

TIEMS chapters play the main role as hosts of TIEMS international events, and the TIEMS Japan Chapter will be the host of TIEMS's next annual conference in 2014, in Niigata, Japan, on October 21-23, with the support of the Governor of Niigata. The date coincides with the anniversary date of the big 2004 Niigata earthquake. One of the main topics in Japan will be focused on experiences with past disasters in the Niigata area.

TIEMS believes in a global dialogue to learn from the exchange of expert information and experience between all stakeholders involved in emergency and disaster management. Last year, TIEMS arranged ten conferences and workshops around the world in Japan, the US, Iraq, Finland, China, France, and Germany. They focused on important and timely topics in emergency and disaster management. In 2014, TIEMS has so far planned 13 conferences and workshops in the US, Japan, Iraq, China, and Finland. We expect additional 2014 workshops and conferences will be arranged by other TIEMS chapters.

TIEMS also initiates and takes part in research and development projects that aim at developing and/or improving methods and technologies in emergency and disaster management. TIEMS is also developing an International Education Training and Certification Program in Emergency and Disaster Management. The International Education Program is composed of TIEMS Chapter Training and TIEMS QIEDM (Qualifications in International Emergency and Disaster Management) Certification. More details are found on TIEMS web site at www.tiems.org.

The TIEMS network constitutes a large international, multidisciplinary group of experts with different educational backgrounds and various experiences in the field of emergency and disaster management. They represent a unique source of expertise and ideas, which are important for creating resilient societies.

TIEMS's latest initiative, which was launched by the TIEMS China Chapter and discussed during the TIEMS annual conference in France, is to establish TIEMS Task Force Groups.

Each TIEMS Task Force Group would comprise qualified TIEMS scientists in different fields and from different cultures. These task groups could cooperate with UNOCHA and/or other international organizations and/or with local emergency management government agencies and directly join in emergency management operations when they occur.

During the TIEMS China Chapter Symposium on Emergency Medical Care in Guangzhou, China, in 2013, TIEMS Emergency Medicine and TIEMS Education, Training, and Certification Task Force Groups were established.

TIEMS believes its exceptional network of qualified and experienced international experts is in a unique position to assist in the creation of more resilient societies worldwide. We believe our resources are particularly well-suited to enhancing disaster preparedness in vulnerable countries by helping to build international alliances and increasing global expertise in emergency management.

\section{FURTHER CONSIDERATIONS FOR GLOBAL PREPAREDNESS}

Disaster-prone countries need to formulate and implement strategies, plans of action, and programs for disaster risk reduction. They should develop their 
institutional and technical capabilities in order to cope with disasters. Preparedness and preventive measures are highly desirable to reduce the disaster losses. Effective and efficient response and rehabilitation capabilities are also equally important to minimize and redress disaster losses and damages. Hence, the need and importance of cooperation and coordination among the national/international organizations and countries is pertinent, particularly in the field of the development of humanitarian assistance (Central Asia Regional Economic Cooperation, 2006).

Disasters must also become a core international development issue. Integrating disaster risk reduction into development policy, programs, and practice is of great importance. It needs to be ensured that disaster risk reduction is included in Poverty Reduction Strategy papers and development plans and programs (Sahana Software Foundation, 2013).

To give an example of the benefits of the disaster risk reduction approach, the World Bank recently estimated that, on an average, countries can save $\$ 7$ in disaster recovery costs for every $\$ 1$ spent on risk reduction measures (Jaurequi et al., 2011). On the other hand, better systems for the collection, analysis, and dissemination of disaster impacts are important. By establishing performance targets linked to climate change, health, and livelihoods, progress can be assessed, and disaster risk reduction can be better integrated into both humanitarian and development efforts.

The international community can further enhance global preparedness through the following:

- Reinforce links between preparedness and response-incorporate learning from disasters into preparedness and allocate sufficient emergency budgets to preparedness.

- Identify and remove stovepipes that hinder cooperation and coordination within the humanitarian community (UN agencies, NGOs, INGOs, academic, corporate sectors, etc.).

- Exploit technologies that support collaboration, such as the Disaster Management Information System (DMIS) (Sahana Software Foundation, 2013) software that has been deployed in response to disasters around the world, to share experiences, exchange views, and learn lessons.

- Public information, education, and disaster awareness are crucial. Therefore, it is highly essential to raise disaster awareness and educate vulnerable populations on disaster impact and response. There must be respect for and inclusion and incorporation of local and indigenous knowledge.

\section{A TIEMS INITIATIVE}

Changing climate, population growth, and other factors conspire to make vulnerable world populations increasingly at risk of loss of life and property due to disasters. The international community is more than willing to help these populations, as evidenced by the outpouring of aid after disaster strikes. The benefits of international cooperation and coordination are very clear. However, attempts to function as a global community are often hampered by the challenges of coordination across cultures and organizations. Coordination can be particularly difficult without the pressure of ongoing emergencies, making efforts at global preparedness even more difficult.

TIEMS believes global emergency preparedness can be improved and losses in particularly vulnerable areas reduced through:

1. Establishment and dissemination of a standardized base of emergency management knowledge inclusive of and adaptable to local knowledge and conditions;

2. Greater emphasis by the international aid community on preparedness versus response in vulnerable regions.

TIEMS has established an initiative to catalyze these improvements, Disaster Resilience Establishment in Vulnerable Societies (DREVS). All stakeholders, including media, are invited to participate. The initiative has two initial thrusts:

- The first is the TIEMS Qualifications in International Emergency and Disaster Management (QIEDM) Certification program (www.tiems.org).

- The second is the creation of a pilot project and demonstration of international collaboration for disaster preparedness.

The Philippines is a prime candidate for this demonstration. Details on this pilot project are forthcoming, and organizations and individuals interested in participating are encouraged to contact the authors.

\section{REFERENCES}

Bandyk, M. (2010, March 24). Why natural disasters are more expensive-but less deadly. US News and World Report. Retrieved from http://money. usnews.com/money/business-economy/articles/ 2010/03/24/why-natural-disasters-are-moreexpensivebut-less-deadly 
Central Asia Regional Economic Cooperation. (2006, August 28-29). Regional cooperation of disaster management and preparedness. Urumqi, XUAR: Central Asia Regional Economic Cooperation.

Chhetri, M. P. (1999). Disaster management in Nepal: Problems and solutions. In J. E. Ingleton (Ed.), Natural disaster management. Leicester: UK: Tudor Rose Holdings, Ltd.

Chhetri, M. P. (2001). Mitigation and management of floods in Nepal. Kathmandu, Nepal: Ministry of Home Affairs.

Drager, K. H., Hagen, J. C., Chhetri, M. B., \& Steiner, N. (2013). Multi-coopoeration in natural hazards warning and mitigation. Paper presented at Pacem in Maribus XXXIV International Forum on Sustainable Governance of the Ocean, Bangkok, Thailand.

Hagen, J. C. (2010). Cross-cultural aspects of disaster reconstruction: importance of lessons learned from indigenous cultures. Paper presented at the International Symposium 5.12 Massive Wenchuan Earthquake Reconstruction and Catastrophic Disaster Control, Chengdu, China.

Hagen, J. C. (2012). Disaster management core competencies in global disaster management. Paper presented at the TIEMS workshop, Resilient Asia: Implementing international emergency management system, Tokyo, Japan.

Hagen, J. C., \& Hagen, S. P. (2013). The immediate post-disaster reconstruction phase: alternate care settings and vulnerable populations. In R. Arora \& P. Arora (Eds.), Disaster management: Medical preparedness, response, and homeland security (pp. 575-590). Wallingford, Oxfordshire: CABI. http://dx.doi.org/10.1079/9781845939298.0575

Jaurequi, C., Sholk, J., Radday, A., \& Stanzler, C. (2011). International disaster response. Boston, MA: Social Impact Research.

Kahn, M. E. (2005). The death toll from natural disasters. The Review of Economics and Statistics, 87(2), 271-284. http://dx.doi.org/10.1162/ 0034653053970339

Ministry of Home Affairs. (1998). Problems of disaster management in nepal and measures to solve them. Kathmandu, Nepal: Ministry of Home Affairs.

Research and Markets. (2014, February 11). Worldwide emergency management and incident market forecasts and analysis. Dublin, Ireland: Research and Markets.

Sahana Software Foundation. (2013). Sahan software foundation. Retrieved from http://sahanafoundation.org

Scholtens, A. (2008). Controlled Collaboration in Disaster and Crisis Management in the Netherlands, History and Practice of an Overestimated and UNderestimated Concept. Journal of Contingencies and Crisis Management, 16(4), 195-207. http://dx.doi.org/10.1111/j.14685973.2008.00550.x

Vinck, P. (Ed.). (2013). World disasters report 2013: Focus on technology and the future of hamanitarian action. Geneva, Switzerland: International Federation of Red Cross and Red Crescent Societies. Retrieve from https://www.ifrc. org/PageFiles/134658/WDR\%202013\%20 complete.pdf 